\title{
A biochemistry discipline designed for the nutrition course
}

\author{
A.A.G.Bianco and B.B.Torres
}

Depto. de Bioquímica - Inst. de Química - São Paulo

Biochemistry is widely considered an essential background in a Nutrition Course framework. At the Faculdade de Saúde Pública, USP, it is a direct requirement to eight disciplines of the syllabus and an indirect requirement to another nine disciplines. Nevertheless, a previous interview study involving Nutrition students and Nutritionists revealed a contradictory image of Biochemistry. Although students and Nutritionists admitted the important role played by Biochemistry, most of the respondents declared that they could not foresee any application of Biochemical contents in their professional life. Aiming to change this situation, a deep intervention in the Biochemistry discipline was carried on. The discipline was planned in such a way that all the contents to be taught was directly derived from subjects or situations matching the interests of nutrition students. Instead of a classical lecture based course, collaborative learning was the methodological choice, taking advantage of practical activities involving educational software and laboratory work as well. The course was carried on in 180 hours and a variety of strategies were employed, especially small group discussion and problem solving. The students were given a booklet containing all the exercises and problems, which acted as course guide. At the end of the course, an evaluation survey was carried out. It is noticeable that, according to students answers: $100 \%$ agreed that Biochemistry was intimately linked to Nutrition; $83 \%$ appreciated the didactical methodologies employed; $89 \%$ would like to continue studying Biochemistry in a further discipline; $96 \%$ declared that the discipline has raised their interest in Biochemistry. In respect to the assessment of the students, these results are in accordance with the opinion of teachers and TAs engaged in restructuring Biochemistry courses.

Supported by CAPES 